\title{
Application of multimedia in individualized teaching of urology
}

\author{
Jinguo Wang ${ }^{1, \text { a }}$, the corresponding author: $\mathrm{Na} \mathrm{Wang}^{2, \mathrm{~b}}$ \\ and Yang Gao ${ }^{3, \mathrm{C}}$ \\ ${ }^{1}$ Department of Urology, the First Hospital of Jilin University, China \\ ${ }^{2}$ Department of Anesthesiology, the First Hospital of Jilin University, China \\ ${ }^{3}$ Department of Anesthesiology, the First Hospital of Jilin University, China \\ awangjinguolily@163.com, bwangna080613@163.com,975707998@qq.comc
}

Key words: urology, multimedia, clinical teaching.

Abstract. According to the characteristics of teaching of urology, teaching can be applied individually in accordance with students' aptitude in the teaching of urology. By switching the teacher-centered class to the learner-centered discussion, we can build multidimensional learning environment, guide the students to learn autonomously and promote learning initiative and enthusiasm of the students.

\section{Introduction}

Through analyzing the features of urological teaching, we discussed the problems exiting in urological teaching. Some advice was provided about how to solve these problems by applying multimedia to clinical teaching.

Clinical urology surgery is clinical specialized fundamental course, it requires students to master the urology surgery related basic knowledge of the basic theoretical knowledge, clinical and clinical related basic operation technology. At the same time, clinical urology surgery is a technologyintensive discipline, therefore, the actual work ability is the core of this stage teaching [1].

Over the years, the teaching pattern of clinical urology surgery is lectures is given priority to, cooperate with the homework, answering questions, and LABS. The teaching method is single, the teaching effect is not very ideal. The traditional education ideas and methods can not fully adapt to the requirement of modern higher education, Institutions of higher learning in constant exploration, optimization and broaden the existing teaching way and method, To cultivate a solid professional foundation, to solve clinical problems, competitive talents. Teaching way and method of multimodal media and personalized education and training can complement to existing mode, But how to build a new teaching model which should be suitable to the professional, this subject, is the need to explore and research topic [2]. But for urology professional teachers to find pictures, information it is difficult and is time-consuming, animation and video processing difficulty and become the biggest obstacle of multimedia teaching courseware quality, if you have the repository, urology teaching materials for teachers to provide images of typical material, convenient teacher prepares a lesson at the same time, also improve the quality of the courseware.

Application database can greatly simplify the urologist data collecting, sorting and summary process, we summarized according to different purpose, classification, statistics and analysis, also the result of data processing can be output in the form of storage or edit as needed.The computer information retrieval system can real-time online retrieval and medical literature analysis and retrieval system, to quickly find the required documents.Computer multimedia technology has been in the medical teaching and has been widely used in academic exchanges.Made of certain computer software slideshows, graphics options can be automatically formed after the big, input data of 
different types of figure, can use Chinese and English at the same time, with special projection device connection, and illustrated, brightly colored slides or animation.

Multimodal media teaching method is to use a new teaching mode of modern teaching media. According to the different teaching contents of clinical urology surgery and needed to achieve the teaching purpose, Multimedia computer as the center, which combines sound, images, text, animation, the simulated exercise method and other methods to highlight its advantages in teaching this course [3]. Efficient use of multimedia computer assisted instruction teaching clinical basic theoretical knowledge: Multimedia computer assisted instruction is refers to the use of computer multimedia as a medium, the static teaching is a dynamic, stimulate students' initiative and creativity, improve teaching efficiency [4].

At present, clinical urology surgery teaching content more and less class hours, and it is more closely the theory and practice of discipline. The content is limited, taught in traditional teaching methods are hard to explain complex operation, students feel boring, abstract is difficult to understand, hard to improve operation skills.Multimedia computer assisted instruction can make abstract, boring learning content into image, visual and audible dynamic content, and provide realistic performance for the teaching effect, expand people's perception of space and time, make the student understanding of knowledge abstraction into a multidimensional concept, so as to mobilize the students' ability to understand knowledge, to cultivate students' ability to analyze and solve problems. After students enter the stage of clinical practice, to recall the content of the lectures, after clinical practice to deepen impression internship can handy operation.

Multimedia computer assisted instruction teaching content is very rich, in addition to the present basic knowledge on the teaching content, also pay attention to the extension and expansion of knowledge, make students really experience at this stage: Aside from gaining knowledge about existing should constantly summarize and found the problem, so as to cultivate the students' scientific research consciousness [5]. Cystoscope bladder tumor resection, for example, teachers can use multimedia courseware in teaching or site presents the basic anatomy and operation main points of the intubation, can also be demonstrated its indications, contraindications, avoid to cause the students in the later processing problem in practical work simplification and simplistic [6]. .

Using the clinical skills to consolidate students' basic knowledge of clinical experiment method: Clinical skills is an important part of medical students' knowledge and ability training of clinical skills experiment teaching of high effect is guarantee to ensure the quality of medical graduates. Upon completion of classroom teaching, students must pass teaching doctors explain operation point, live to learn and master the skill in teacher under the guidance of operation process, such as gradually. Design a clinical case, students choose drugs, after thinking and make students see what drug effect immediately. This pattern that left a deep impression on students, be clear at a glance. This kind of teaching method to let the students as the main body of practice, arouse the enthusiasm of the students greatly.

Over the years, I combine the multimedia computer assisted instruction used in anesthesia clinical practical teaching [7]. Teaching practice shows: The multimodal media teaching method not only brings out the advantages of teaching resources, and accord with the requirement of medical students' learning, is of clinical urology surgery teaching contents, teaching methods, teaching methods reform. It give full play to the students and teachers' leading role and improve the students' interest in learning, active classroom atmosphere, improve the students' autonomous learning ability, cultivate students' ability of independent thinking, analysis, solve the problem. At the same time, the multimodal media teaching is beneficial to improve the quality of teaching, is helpful for students to consolidate the theoretical knowledge, strengthening clinical contact, sets up the preliminary scientific research students view, to the cultivation of medical students' practice ability has played a positive role [8]. Enhance their learning ability as well as creative ability, promote the 
communication and cooperation of teachers and students, and improve teaching quality. It is generally assumed that incoming students in medical education programs will be better equipped for the "digital age" given their younger age and an educational upbringing in which technology was seemingly omnipresent. In particular, many assume that today's medical students are more likely to hold positive attitudes and increased comfortability with technology and possess greater information technology (IT) skills [9]. Today's incoming veterinary medical students tend to indicate the same desire to improve skills using spreadsheets and web page design as incoming students from 10 years ago. It seems that despite technological advances and increased exposure to such applications and skills, there remains a challenge for students to "keep up" with the ever evolving technology. Moreover,

although students continue to report they are very comfortable with using a computer (and related devices), many use their computers as typewriters or word processors, as opposed to a means for performing more advanced computing functions [9].

In a word, in the information society, with a core of multimedia teaching in the classroom is an important symbol to measure the level of modern medical education, multimedia education technology research and development is important topic in the study of medical teaching. Sure the use of multimedia teaching methods can increase the teaching effect of urology, the quality of teaching to a new level.

Teachers should adapt to the new situation of teaching reform, and constantly develop and the development of multimedia courseware, innovation and enriching the content of the courseware, and in order to better promote the development of students' comprehensive quality longitudinal

\section{Conclusions}

This kind of teaching method is more suitable for long-term education compared with arbitrary single model.

\section{References}

[1] Han H, Nelson E, Wetter N. Medical students' online learning technology needs. Clin Teach. 11, 15-19 (2014).

[2] Milford E, Morrison K, Teutsch C, Nelson BB, Herman A, King M, Beucke N. Out of the classroom and into the community: medical students consolidate learning about health literacy through collaboration with Head Start. BMC Med Educ. 16, 121 (2016).

[3] Rajab LD, Baqain ZH. Use of information and communication technology among dental students at the University of Jordan. J Dent Educ. 69, 387-98 (2005).

[4] Link TM, Marz R. Computer literacy and attitudes towards e-learning among first year medical students. BMC Med Educ. 19, 34 (2006).

[5] Hendricson W, Eisenberg E, Guest G, Jones P, Johnson L, Panagakos F, McDonald J, Cintron

L. What do dental students think about mandatory laptop programs? J Dent Educ. 70, 480-99 (2006).

[6] Seago BL, Schlesinger JB, Hampton CL. Using a decade of data on medical student computer literacy for strategic planning. J Med Libr Assoc. 90,202-9 (2002).

[7]. Forman LJ, Pomerantz SC. Computer-assisted instruction: a survey on the attitudes of osteopathic medical students. J Am Osteopath Assoc. 106, 571-578 (2006). 
[8]. Buabbas AJ, Al-Shawaf HM, Almajran AA. Health Sciences Students' Self-Assessment of Information and Communication Technology Skills and Attitude Toward e-Learning. JMIR Med Educ. 20, 2(1):e9 (2016).

[9]. Kenneth Royal, Mari-Wells Hedgpeth, Dan McWhorter. Students' Perceptions of and Experiences With Educational Technology: A Survey. JMIR Med Educ. 2,e4 (2016). 